\title{
O DOCENTE COMO PROPAGADOR DA EDUCAÇÃO AMBIENTAL POR MEIO DA CONDUTA DIÁRIA NO AMBIENTE ESCOLAR
}

\author{
THE TEACHER AS A PROMOTER OF ENVIRONMENTAL EDUCATION THROUGH \\ DAILY CONDUCT IN THE SCHOOL ENVIRONMENT
}

\section{RESUMO}

A propagação da Educação Ambiental é uma necessidade global diante dos impactos negativos que o meio ambiente tem sofrido e deve ser inserida de forma transversal no currículo, nas práticas de ensino-aprendizagem, de forma intencional e objetiva para sensibilização das pessoas, promovendo as mudanças de hábitos. O docente deve envolver alunos e demais componentes das unidades escolares em projetos de sustentabilidade de forma organizada e contextualizada. O objetivo da pesquisa foi analisar as metodologias que um docente de terceiro ano do ensino fundamental do município de Navegantes-SC trabalha a educação ambiental com seus alunos, sendo que a metodologia adotada foi a de pesquisa-ação, com questionários para os alunos e para a professora, além da análise do plano de ensino, entregue à direção escolar, com a intenção de verificar se de fato são promovidas atividades que estimulam e sensibilizam as pessoas para que haja a diminuição na degradação ambiental. Os resultados apresentados foram positivos, pois não ocorreu contradição entre as afirmações da docente que enfatizou realizar muitas aulas de educação ambiental e as respostas dos alunos nas entrevistas. Porém, apesar da docente parecer se importar com as questões ambientais, não foi encontrado conteúdo ou atividade sobre Educação Ambiental no plano anual, revelando o descaso com o tema que é transversal e deve estar presente nesse documento, que é norteador para todas as aulas do ano. A pesquisa comprova que há falha no sistema de ensino quanto à visão que se tem em sensibilizar o ser humano, por não se cobrar uma continuidade no tema Educação Ambiental de forma abrangente e interdisciplinar.

Palavras-chave: Educação Ambiental. Metodologias. Sensibilização.

1 Pedagoga da Rede Municipal de Navegantes-SC. E-mail: flaviagracykelly@gmail.com

2 Doutoranda em Ciência e Tecnologia Ambiental pela Universidade do Vale do Itajaí (UNIVALI). E-mail: anabelamafra@yahoo. com.br 


\section{ABSTRACT}

The propagation of Environmental Education is a global necessity in view of the negative impacts that the environment has suffered and must be inserted transversally in the curriculum, in the teaching-learning practices, in an intentional and objective way to sensitize people, promoting changes in the environment. habits. The teacher should involve students and other components of school units in sustainability projects in an organized and contextualized manner. The objective of the research was to analyze the methodologies that a third year teacher of the elementary school of the municipality of Navegantes-SC works the environmental education with their students, and the methodology adopted was the action research, with questionnaires for the students and for The teacher, in addition to the analysis of the teaching plan, delivered to the school board, with the intention of verifying if in fact are promoted activities that stimulate and make people aware of the reduction in environmental degradation. The results presented were positive, as there was no contradiction between the statements of the teacher who emphasized taking many environmental education classes and the students' answers in the interviews. However, although the teacher seems to care about environmental issues, there was no content or activity on Environmental Education in the annual plan, revealing the disregard with the theme that is transversal and should be present in this document, which is guiding for all classes of year. The research proves that there is a flaw in the education system regarding the vision that has to sensitize the human being, for not demanding a continuity in the theme Environmental Education in a comprehensive and interdisciplinary way.

Keywords: Environmental Education. Methodologies. Awareness.

\section{INTRODUÇÃO}

A prática da Educação Ambiental é uma forma de respeitar o meio ambiente em que se vive, repensando, reutilizando, reciclando e causando menos impactos ambientais negativos.

Os temas de Educação Ambiental devem ser trabalhados de forma que envolvam os alunos, levando-os a repensarem suas atitudes.

Mesmo sabendo que a sociedade, em sua maioria, é consciente da importância de preservar o meio ambiente é necessário que se promova, através de exemplos pessoais, hábitos saudáveis e conduta ética em ambientes onde se realiza educação. Há, porém, omissões no desenvolvimento de atitudes ecológicas quando se pratica repetidas vezes atos que agregam na valorização da natureza. 
Por meio de estratégias de educação ambiental é que se alcança a sensibilização da sociedade, para que se possa controlar parte da degradação ambiental que a sociedade produz.

O envolvimento de estudantes em projetos com temas ambientais é um incentivo para torna-los promotores de ações que amenizem impactos negativos no meio ambiente; deixando de serem apenas ouvintes de informações, mas agentes conscientes da realidade e que estejam dispostos a zelar pela natureza, evitando a degradação da natureza e seus recursos.

A fim de refletir o quanto o desempenho do professor no ambiente escolar pode contribuir com a preservação do meio ambiente, por meio da união do corpo docente de forma interdisciplinar e compreendendo a educação ambiental como uma necessidade coletiva, esta pesquisa busca realizar a análise de como são abordadas as atividades voltadas às questões ambientais; verificando as metodologias usadas e o plano de ensino anual.

Inserir a Educação Ambiental de forma transversal para que o aprendizado do aluno possa ser inserido nas suas ações dentro e fora da escola é essencial para o ambiente se tornar mais sustentável. As práticas de Educação Ambiental não devem ser realizadas de forma obrigatória, é fundamental que haja sensibilização sobre a grave situação dos impactos ambientais negativos do planeta.

É vital e importante a inserção da Educação Ambiental no currículo como forma de sensibilização a todas as camadas da sociedade, porém quando este tema é implantado em escolas, deve ser realizado de forma cautelosa para que não seja fomentado como disciplina separada ou ainda como um evento pontual (MAFRA, 2015, 27).

O docente pode integrar a educação ambiental ao plano de ensino já que o terceiro ano tem apenas um professor que leciona em todas as disciplinas, envolvendo todos os conteúdos e assim pode trabalhar a sustentabilidade de forma interdisciplinar.

A mediação do docente que desenvolve Educação Ambiental tem o intuito de construir novos saberes e criar oportunidades além da vivência da sala de aula, acontecendo um encontro democrático e a troca de experiências com os alunos.

O papel dos professores é de extrema importância, uma vez que eles são mediadores desse conhecimento e têm por função levar o aluno a entender a complexidade com que convive, desde seus problemas até suas soluções, bem como de sua responsabilidade no processo de construção de uma sociedade mais consciente e sustentável (JACOB, 2003, 87).

A partir de realizações de atitudes sustentáveis no ambiente escolar a tendência é que haja uma mudança de comportamento dos alunos durante as aulas. 
O desafio da mudança de hábitos ecológicos consiste na percepção de que a Educação Ambiental pode transformar a situação do meio ambiente em que se está inserido e, consequentemente, proporcionar melhor qualidade de vida para as pessoas.

O objetivo desta pesquisa foi analisar como e com qual frequência a educação ambiental é abordada em uma sala de aula de um $3^{\circ}$ ano de Ensino Fundamental; pois a população infantil é agente de grande consumo quando escolhe brinquedos, roupas e determinados alimentos. Sendo assim, se faz necessário analisar como o docente trabalha com educação ambiental e quais os resultados dessas atividades voltadas à natureza.

\section{REVISÃO BIBLIOGRÁFICA}

Ao perceber que pequenas mudanças nos hábitos diários podem transformar o modo de vida de várias pessoas dispostas a terem hábitos mais saudáveis e ecológicos, fica evidente a importância do docente como promotor da Educação Ambiental, através da conduta diária no ambiente escolar.

Entretanto, quando se dá continuidade às atividades de Educação Ambiental, fazendo disso um costume diário entre os educadores, com certeza os resultados podem ser ainda melhores.

Salienta-se que dentro da escola é onde começam as imitações por intermédio da curiosidade aguçada pelo mestre, e de lá saem as ideias propostas e construídas. Sendo assim a sociedade pode se constituir de seres ecológicos capazes de causar impactos positivos no meio ambiente.

Compreende-se que não basta incorporar o tema Educação Ambiental como conteúdo no currículo escolar sem que ele faça parte do dia-a-dia do docente, que é visto como modelo, pois bons hábitos partem de bons exemplos.

Os valores e atitudes em Educação Ambiental necessitam do desenvolvimento de uma consciência crítica que leve à mudança de atitudes, à ressignificação de valores fundamentais nos processos educativos, de forma a desenvolverem novas habilidades e competências, visando minimizar os problemas socioambientais e instigando ações efetivas, que possibilitem à população uma melhoria da qualidade de vida. Ainda, é necessário que estas mudanças de visão de mundo, de ser humano e nossas interações com o planeta ocorram de forma permanente. Por isto, a discussão dessa problemática precisa ser incluída desde a educação infantil, incorporando também as dimensões: socioeconômica, política, cultural, histórica, ética e estética (MAFRA, 2018, 37).

Todo educando inserido com atividades de educação ambiental pode e deve usar seu "poder", expandindo a sustentabilidade ambiental.

Segundo Barcelos $(2012,98)$, é uma mentira afirmar que educação ambiental é coisa para os professores de ciências, biologia ou geografia. 
Três dos princípios definidos pela Conferência Intergovernamental de Educação Ambiental de Tbilisi, em 1977, como princípios da Educação Ambiental a ser desenvolvida nas escolas, são: Estabelecer, para os alunos de todas as idades, uma relação entre a sensibilização ao meio ambiente, a aquisição de conhecimentos, a atitude para resolver problemas e clarificação de valore, procurando, principalmente, sensibilizar os mais jovens para os problemas ambientais existentes na sua própria comunidade; Ajudar os alunos a descobrirem os sintomas e causas reais dos problemas ambientais; Ressaltar a complexidade dos problemas ambientais e, em consequência, a necessidade de desenvolver o sentido crítico e as atitudes necessárias para resolvê-los (UNESCO, 1977, 2-5).

Analisando criteriosamente cada conteúdo dos seriados, filmes, novelas, propagandas entre outros, voltados para crianças e adolescentes, é possível perceber o apelo aos seguimentos de moda e consumo de produtos. Esse assunto por muito tempo era comum ser abordado nas disciplinas de ciências e geografia, como se fosse apenas um problema onde a solução se daria se daria se fossem abordados em alguns momentos específicos.

Entretanto os vídeos que são utilizados estrategicamente para auxiliar no ensino e aprendizagem na escola abordam o tema em várias perspectivas, dando aos alunos a autonomia para criticidade, autoanálise e reflexão. Isso não precisa ser em datas, horas e disciplinas específicas.

Pereira $(2007,56)$ conclui que a mídia tem uma grande participação no que diz respeito à formação da criança, tão fortemente quanto à escola, representando a disseminação de ideias conformistas e controle da população.

Ao educando é indispensável que seja apontada a tentativa de transformar atitudes e valores, visando apontar caminhos que tornem possível o desenvolvimento com um mínimo de agressão ao meio ambiente, incentivando certos procedimentos para a sustentabilidade e melhoria da qualidade de vida e proteção à saúde ambiental, a curto, médio e longo prazos; prorrogando o tempo de utilização dos bens e serviços naturais e dando chance às gerações futuras de também poderem se valer deles para as suas necessidades (MAFRA; GUERRA, 2010, 12-13).

Entretanto todo docente pode e deve chamar atenção dos alunos para a valorização ambiental, sem que essa responsabilidade seja apenas do docente específico em Educação Ambiental.

Quando o docente tem uma meta que para ele é importante, sua conduta naturalmente passa a ser motivadora e seu aluno, na condição de aprendiz, repetirá seus atos. Reaproveitar os materiais ou restos deles que iriam degradar a natureza não implica somente expor a criatividade e sim estimular que gestos simples sejam adotados, levando a resultados surpreendentes como a sensibilização e a reflexão em massa. 
O que mais mobiliza tanto as crianças quanto os adultos a respeitar e conservar o meio ambiente são o conhecimento das características, das qualidades da natureza; é perceber o quanto ela é interessante, rica e pródiga, podendo ser ao mesmo tempo muito forte e muito frágil; e saber-se parte dela, como os demais seres habitantes da Terra, dependendo todos- inclusive sua descendência- da manutenção de condições que permitam a continuidade desse fenômeno que é a vida, em toda a sua grandiosidade. (BRASIL, 1997, 11).

Isso reforça que a Educação Ambiental não pode ser trabalhada de forma isolada em determinadas disciplinas, pois são valores que devem fazer parte do cotidiano do educador, bem como estar presente em todos os espaços educativos, da creche aos cursos de pós-graduação.

A Educação Ambiental nessa perspectiva apresenta um caráter interdisciplinar, onde sua abordagem deve ser integrada e contínua, e não ser uma nova disciplina, ou seja, "A Educação Ambiental não deve ser implantada como uma disciplina no currículo de ensino em conformidade com a lei 9.795/99 (BRASIL,1999).

Desde cedo, as crianças devem obter hábitos de vida ambientalmente corretos, e para que isso aconteça precisam ter exemplos daqueles que exercem influência sobre esses alunos, seus professores (NARCIZO, 2009, 57).

Em várias ocasiões, o docente pode pondo-se colocar estrategicamente como exemplo a ser seguido; como chegar à escola de bicicleta ou dividir o transporte com outro colega docente; dessa forma pode abrir uma discussão e falar sobre o engarrafamento no trânsito que agrava ainda mais a polvição por conta do combustível, entre outras formas de fazer com que os alunos reflitam e repassem as informações para a família, e que, os resultados obtidos pelos docentes que aderem às opções ecológicas sejam imitados e tornem projetos de sustentação na unidade, visando não apenas abranger a escola, mas expandir a ideia alcançando um número considerável de pessoas sensibilizadas e comprometidas com a sustentabilidade.

Existe então a necessidade de se adotar uma EA desde as séries iniciais, através de um processo permanente, desde o início da Educação Infantil até a fase final do ensino formal. Entretanto, essa educação só se faz relevante quando é trabalhada de forma diferenciada, contínua e no contexto local das crianças, rompendo com as práticas que se restringem a atuações esporádicas, superficiais e equivocadas. (HENN, 2008, 86).

É comum que os alunos recebam informações sobre Educação Ambiental em datas específicas, como dia da árvore, que é uma das datas que ganha espço durante o ano; isso quando o docente "acha" importante inserir algo sobre o tema no plano de ensino.

A criança deve aprender que a responsabilidade ambiental é de todos e que o amanhã está amarrado aos atos de cada indivíduo (EFFTING, 2007, 78). 
Portanto, a Educação Ambiental deve trabalhar a relação do homem com a natureza nas escolas de forma interdisciplinar, numa visão sistêmica, estimulando a percepção da inter-relação entre os fenômenos, para a compreensão da problemática ambiental e para o desenvolvimento de uma visão articulada do ser humano em seu meio natural, como construtor e transformador deste meio (BRASIL, 2000).

A escola precisa ser o lugar onde todo e qualquer assunto relacionado à sobrevivência e bem-estar populacional seja explanado e explorado, sendo todo corpo docente responsável por fornecer respaldo nesse quesito. Assim, é muito importante a troca de informações para que o plano de ensino seja elaborado pensando de maneira clara e objetiva, a ponto de ser percebida a preocupação com o planeta em todos os conteúdos.

Ao se referir à crise ambiental, a reconhece como uma crise que veio para questionar os fundamentos ideológicos e teóricos que impulsionaram e legitimaram o crescimento econômico, "negando a natureza e a cultura, deslocando a relação entre o Real e o Simbólico" (LEFF, 2006, 76).

Segundo 0 Artigo $1^{\circ}$, da Lei $n^{\circ}$ 9.795, de 27 de abril de 1999, a Educação Ambiental corresponde aos processos por meio dos quais o indivíduo e a coletividade constroem valores sociais, conhecimentos, habilidades, atitudes e competências voltadas para a conservação do meio ambiente, bem de uso comum do povo essencial a sadia qualidade de vida e sua sustentabilidade (BRASIL, 1999).

Considera-se o fato que a criança ainda está em fase de formação moral, fazer compras de produtos que nem são necessários só porque o amigo de turma ou um parente adquiriu, sendo que para a mesma não há nada de errado nessa atitude, ela não nasceu consumista e nem sabe se tal conduta é prejudicial ou não.

Carvalho $(2012,27)$ salienta que a Educação Ambiental reside na tomada de decisão da responsabilidade do indivíduo perante o mundo em que vive com os outros seres e com o ambiente, ou seja, na atitude de intervir nos problemas e conflitos ambientais contribuindo para a mudança de valores e atitudes.

Émuito comum assistirmos em telejornais matérias apontando as preferências do público infantil, se referindo ao consumo de todo tipo de mercadorias que varia entre roupa, brinquedos, alimentos, entre tantos outros itens comercializados, e assim o incentivo ao consumo se torna algo muito comum.

Apesar de se ter esse conhecimento e embora não seja tão recente, ainda é preocupante, pois se pode perceber o quanto as crianças ainda influenciam no consumo, através de seus materiais escolares, por exemplo, o quanto trocam de caderno por arrancarem folhas a cada erro de escrita e os lápis que são substituídos a cada semana, sem contar as mochilas que deixaram de ser um objeto de proteção para os materiais necessários, se tornando parte do material ostentação 
e, essa é trocada a cada ano e muitas vezes também vai para o lixo, já que a população infantil vem demonstrando autonomia no poder de escolha e influência no consumo.

Os docentes têm função essencial na inclusão da educação ambiental na sucessão dos dias letivos, difundindo temas para discussão de forma crítica sobre a crise socioambiental, tendo como meta a transformação de costumes e práticas sociais e a produção de uma cidadania ambiental que promova a sustentabilidade (MAFRA, 2018, 50).

Nesse cenário, o mundo da criança é invadido com a mesma força e artimanha utilizadas para os adultos, fiéis compradores; isso porque "não é necessária nenhuma habilidade" para comprar nesse mercado. (BAUMAN, 2009, 67).

Os docentes são referências para seus alunos que, na maioria dos casos, copiam seus exemplos; assim, quando alguns profissionais desfilam diariamente com roupas de moda e chamativas, estes são percebidos muitos mais pelo seu visual do que pelos conhecimentos ensinados dentro de sala. Porém, quando os profissionais são percebidos como pessoas realmente preocupadas com o rumo que segue a degradação do meio ambiente e mostram saídas para evitar o consumo excessivo, nota-se a urgência de mudança no comportamento social.

Segundo Mafra $(2015,27)$ a Educação Ambiental deve ter o propósito de promover reflexão, discussão e mudanças nos hábitos diários.

A Educação Ambiental nas escolas é desenvolvida sob duas vertentes: a ecológico-preservacionista, que trata a Educação Ambiental apenas para a conservação da natureza, sem se preocupar com os fatores sociais atuantes; e a socioambiental, que traz a Educação Ambiental numa perspectiva mais ampla de conservação ambiental e mudança social (FREIRE et. al., 2006, 45).

O docente tem uma grande responsabilidade com o meio ambiente, e não é necessário apenas mostrar ou ensinar como cuidar do nosso planeta, e sim se permitir ser visto como exemplo.

\section{METODOLOGIA}

Para que se analise como a Educação Ambiental é abordada em uma turma de estudantes dos anos iniciais, na pesquisa de campo e bibliográfica, foram utilizados como procedimentos, a escolha de um docente e de uma turma de $3^{a}$ ano do Ensino Fundamental do município de Navegantes, SC.

$O$ plano anual de ensino do $3^{\circ}$ ano do Ensino Fundamental do docente escolhido foi analisado para descrever como a educação ambiental é apresentada, organizada e realizada para sensibilização ambiental. Esse plano foi verificado por bimestre comparando os conteúdos e atividades desenvolvidas. 
As entrevistas com os estudantes do $3^{\circ}$ ano abordando as atividades de educação ambiental que o docente realizou com a turma, foram desenvolvidas com um questionário com alternativas objetivas, as quais tinham linhas para poderem dar exemplos de atividades que os alunos consideravam educação ambiental. Todas as entrevistas foram lidas pela pesquisadora e o docente não estava na sala de aula no momento da aplicação.

A entrevista com o docente da sala do $3^{\circ}$ ano ocorreu sem a presença de alunos e com questionamentos sobre sua prática nas atividades de Educação Ambiental. A pesquisadora conversou sobre os questionamentos da entrevista com o docente deixando aberto para o mesmo acrescentar informações pertinentes.

A técnica da aplicação dos questionários foi baseada em Pádua $(2007,81)$ que enfatiza a importância da análise qualitativa em entrevistas e que pode ser analisada pela análise do conteúdo e análise do discurso.

Nas análises das entrevistas do docente e dos alunos foram feitas a verificação e comparação das atividades de educação ambiental descritas.

\section{RESULTADOS E DISCUSSÕES}

Durante a visita foi conversado com o docente da turma de $3^{\circ}$ ano do Ensino Fundamental da rede municipal de Navegantes, que se mostrou realmente preocupado em sensibilizar os alunos quanto a preservação do meio ambiente; começando com o cuidado do espaço da sala de aula.

Rodriguez e Silva $(2009,57)$ alertam que as mudanças de atitudes e as práticas de Educação Ambiental só promovem transformações de valores, de comportamento e ações para a formação da cidadania plena quando a sustentabilidade ambiental for articulada com o comportamento, a mentalidade e o pensamento do indivíduo.

Ao entrevistar o docente, que já atua há 20 anos na área educacional, verificou- se nas respostas falas coerentes, porém desconectadas do plano de aula anual que, ao mesmo tempo em que engloba a reutilização e reaproveitamento de materiais como: tampinhas, canudos, palitos e recortes; também promove o consumo intenso de outros materiais como cartolinas e folhas sulfites. Isso analisando o método de avaliação elaborado para os quatro bimestres, no qual a mesma faz muito uso de folhas impressas.

O docente afirmou que durante o período de faculdade foi informada quanto a sua importância como promotor da Educação Ambiental no âmbito escolar, e que, na sua concepção tem o compromisso de incentivar os alunos nas suas potencialidades, na sua visão crítica e construtiva em relação ao meio em que vive. Também estimula os alunos a praticarem ações ecológicas, incentivando a sustentabilidade, fazendo-os refletir que suas ações têm consequências boas e ruins 
e que isso também se reflete as atitudes que pratica para ajudar ou não o meio ao qual faz parte.

A Política Nacional de Educação Ambiental considera que a educação ambiental é um componente essencial e permanente da educação nacional, devendo estar presente, de forma articulada, em todos os níveis e modalidades do processo educativo, em caráter formal e não-formal (BRASIL, 1999).

Para que se pudesse analisar se a conduta da docente e o plano de aula são coerentes com o modo com que os alunos compreendem sua parte na conservação da natureza, a mesma apontou mudanças percebidas por ela nas atitudes deles em relação ao meio ambiente, como a questão do reduzir, reutilizar e reciclar, como por exemplo, a separação do lixo sólido.

A educação ambiental na escola ou fora dela continuará a ser uma concepção radical de educação, não porque prefere ser a tendência rebelde do pensamento educacional contemporâneo, mas sim porque nossa época e nossa herança histórica e ecológica exigem alternativas radicais, justas e pacíficas. (REIGOTA, 1998, 80).

$O$ docente do $3^{\circ}$ ano aceitou ser entrevistado e observado, contribuindo com o respectivo artigo, pois afirmou que o crescimento pessoal de uma criança é bastante gratificante.

Esse docente não pensa em apenas repassar conteúdos, seu principal objetivo é fazer os alunos se perceberem como agentes transformadores, onde se tornem conscientes de suas atitudes e que com os saberes aprendidos na escola possam mudar a sua história, do meio em que estão inseridos, tornando-o cada vez melhor. E essa vontade de sensibilizar, estende-se aos demais colegas docentes que são incentivados a assumirem a conduta de promotores da Educação Ambiental, através de suas atitudes e ações que percorrem juntas nas realizações do dia-a-dia.

A Educação Ambiental trata a Educação integrada à cidadania, ao diaa-dia, à formação da consciência ecológica, saindo da sala de aula de forma transdisciplinar, desenvolvendo atitudes ambientalmente corretas (LEFF, 2001, 132).

A entrevista foi também realizada com os alunos que colaboraram com o artigo demonstrando interesse no assunto sustentabilidade. Porém, o que se percebe é a pouca informação ou falta de espaço para ampliação de informações referentes ao tema.

Os 25 alunos que compõem a turma do $3^{\circ}$ ano, afirmaram notar que o docente da sala ajuda a cuidar da natureza com o reaproveitamento de materiais escolares; desses, 19 citaram o reaproveitamento de caixas para guardar objetos, 23 citaram o uso de materiais reciclados, entre eles alguns especificaram materiais reutilizados; 1 citou garrafas pet, 1 citou livros como reutilizáveis; onde esses materiais foram reaproveitados em construções criativas em sala de aula, e 1 lembrou que usar os dois lados da folha também ajuda a não "degradar" o meio ambiente, e esses materiais foram usados para elaboração de avião que foi utilizado na 
abordagem do tema meio de transporte; um vulcão também foi construído para uso em explicações dos conteúdos de geografia, ciências e história e uma ampulheta que auxiliou na aula de matemática.

Os alunos afirmaram que o docente incentiva para que se lembrem de preservar o meio ambiente através de atitudes, entre as afirmações as especificações são bem parecidas, pois atitudes corriqueiras que repete já serve de sensibilização, como: não jogar lixo na rua e reduzir o papel, a coleta seletiva, não jogar lixo no chão e cuidar da sala, não jogar o óleo pela pia, a exposição de vídeos sobre o uso dos "três R's" (reutilizar, repensar e reciclar) que mostra a quantidade de resíduos produzidos.

Apesar de conferir que o tema é abordado em sala de aula durante o ano e esse conteúdo, que envolve educação ambiental, não estar exposto no plano anual, ou seja, não estava organizado e preparado desde o início do ano; verificouse também que o docente pediu para esclarecer umas informações antes de o questionário ser aplicado com a turma. Assim, confirma-se que as respostas tão parecidas e repetidas dos alunos, deram-se pela influência direta do docente que não deixou a turma sozinha para responder a entrevista, interferindo para lembrarse de atividades realizadas em sala.

Como todo aluno que tem seu docente como um bom exemplo, assim é vista o docente dessa turma que tem suas ações ecológicas reconhecidas e reproduzidas por seus alunos.

Todos os 25 alunos da classe afirmaram que durante o ano letivo foram elaboradas e executadas atividades de educação ambiental na escola; como: produção de texto, maquete com materiais reutilizáveis, as restinga, apresentação e jogar lixo na lixeira certa. As crianças também fizeram menção de ações que fazem na escola e que dão continuidade em casa. Um aluno afirma fazer uso dos três RRR (reutilizar, repensar e reciclar), sete alunos jogam o resíduo na lixeira correta, uma aluna alerta a mãe para que não jogue óleo na pia, os demais trazem objetos como pilha para serem jogados nas lixeiras ecologicamente corretas que tem na escola.

Essas são atitudes que devem se tornar corriqueiras, para que sejam cada vez mais imitadas. Entretanto o que se notou foi a impressão de que se fala pouco sobre um assunto tão abrangente. Embora os alunos afirmem que estejam empenhados a sensibilizar a própria família, a educação ambiental, deveria ter mais espaço não só na sala de aula, mas em toda unidade escolar, pois assim abriria um leque de informações que tornariam os alunos mais críticos quanto à forma de pensar e propagar a sustentabilidade.

Entendem-se por educação ambiental os processos por meio dos quais o indivíduo e a coletividade constroem valores sociais, conhecimentos, habilidades, atitudes e competências voltadas para a conservação do meio ambiente, bem de uso comum do 
povo, essencial à sadia qualidade de vida e sua sustentabilidade (BRASIL, 1999).

\section{CONSIDERAÇÕES FINAIS}

O tema Educação Ambiental tem sido uma das preocupações, no que se refere ao ambiente escolar, isso analisando alguns artigos em que enfatizam a necessidade da integração entre docentes para elaborar e desenvolver ações que visam à sensibilização de unidades escolares, com pretensão de expandir para todas as comunidades onde ambas estão inseridas, fazendo com que a preservação da natureza seja uma preocupação de todos, e, fazer refletir quanto à responsabilidade de cada um quanto à degradação que aumenta consideravelmente.

Para que se obtenha êxito no que se propõe é preciso que o primeiro passo seja dado por quem tem a consciência e experiência de que a informação e exemplos se completam quando usados como recursos. Nesse caso o docente é o mais indicado a se habilitar como espelho para que a sociedade o imite, começando por seus alunos que tem como exemplo a ser seguido.

Muitos dos adultos de hoje são reflexos de atitudes de docentes no sentido "ecológico", nisso pode-se perceber a gravidade do problema quando o mestre não se porta como propagador da Educação Ambiental no ambiente escolar e não atua como mediador de conhecimento, afinal que conhecimento poderá ser construído quando não se compreende a importância da natureza?

Podemos concluir que se deve levar em consideração que há falhas no sistema de ensino quanto a visão que se tem em sensibilizar o ser humano, por não se cobrar de forma constante e contínua abrangendo a interdisciplinaridade do tema Educação Ambiental. Em princípio porque é um tema transversal e deveria ser abordado em todas as disciplinas por ser conteúdo do Plano Anval apresentado, porém observou-se que não foi exigido pelos gestores ou supervisores da escola envolvida.

É necessário que estratégias sejam criadas, transformando vidas e atitudes sustentáveis para uma melhor qualidade de vida, podendo iniciar por hábitos saudáveis e ecológicos; partindo de docentes, como por exemplo, a minimização de desperdício de objetos, roupas, papéis, entre outras alternativas. Oreaproveitamento de materiais nas atividades do dia-dia no ambiente escolar, como a fabricação de roupas para teatro, brinquedos que possam se tornar materiais sustentáveis e outros trabalhos que incentivem ações e atitudes louváveis em momentos de tanta preocupação ambiental.

Busca-se mostrar neste artigo que se deve levar em consideração que há falha no sistema de ensino quanto à visão que se tem em sensibilizar o ser humano, por não se cobrar uma continuidade no tema Educação Ambiental de forma abrangente e interdisciplinar. Sabendo que a preservação do meio ambiente é 
uma forma inteligente de resguardar não só outras espécies como também a vida humana e obter melhor qualidade para sua sobrevivência, é imprescindível que cada cidadão tenha posturas mais ecológicas e responsáveis para amenizar a degradação ambiental.

Ser sustentável foge do formato tradicional, ou seja, vai além do ensinar na sala de aula em datas estabelecidas, tornando-se um assunto dinâmico, relevante, que transforma cidadãos, em entes críticos com visão ampla de futuro, abertos a novos conceitos e conhecimentos.

\section{REFERÊNCIAS}

BARCELOS, V. Educação ambiental princípios, metodologias e atitudes. 4 ed. Petrópolis, R.J: VOSES, 2012.

BAUMAN, Z. Globalização: as consequências humanas. Rio de Janeiro: Zahar, 1999.

BRASIL. Ministério da Educação. Parâmetros Curriculares Nacionais: meio ambiente e saúde / Secretaria de Educação Fundamental. Brasília, 1997.

BRASIL. Lei n. 9.795, de 27 de Abril de 1999. Dispõe sobre a educação ambiental, institui a política nacional de educação ambiental e dá outras providências. Diário Oficial da República Federativa do Brasil. Brasília (DF); 28 abr. 1999.

BRASIL. Parâmetros Curriculares Nacionais para o Ensino Médio. Bases Legais. Brasília: MEC/SEMTEC, v.1, 2000.

CARVALHO, I. G. de M. Educação Ambiental: a formação do sujeito ecológico. São Paulo: Cortez, 2012.

EFFTING, T. R. Educação Ambiental nas escolas públicas: Realidade e desafios. Monografia. Paraná, 2007.

FREIRE, J. T.; NASCIMENTO, M. F. F.; SILVA; S. A. H., 2006. Diretrizes Curriculares de Educação Ambiental: as escolas da Rede Municipal de Ensino de Salvador. Salvador:SMEC

HENN, R. BASTOS, F. da P. de. Desafios ambientais na educação infantil. Revista Eletrônica do Mestrado em Educação Ambiental, v. 20, p. 329-349, jan./jun. 2008.

JACOB, P. Educação Ambiental - Cidadania e sustentabilidade. Caderno de Pesquisa, n 118 , p. 189-205, março/2003. Disponível em: < http://www.scielo.br/pdf/ cp/n1 18/16834.pdf>. Acesso em 15 de out. de 2017. 
LEFF, E. Racionalidade Ambiental: a reapropriação social da natureza. Ed. Record, 2006, 555 p.

LEFF, E. Saber Ambiental: Sustentabilidade, Relacionamento, Complexidade. Petrópolis: Vozes, 2001

MAFRA, A. I. A importância de se planejar e orientar previamente eventos ecológicos nas escolas. Revista Ponte.com SINERGIA. Navegantes. v.6, n.7, jan./jun. 2015. p.2531.

MAFRA, A. I. Educação Ambiental na formação continuada de professores. Revista Ponte.com SINERGIA. Navegantes. v.9, n.13, jan./jun. 2018. p.47-55.

MAFRA, A. I.; GUERRA, A. F. S. Formação continuada para educadores ambientais: reflexões e considerações. In: VIII Encontro de Pesquisa em Educação da Região Sul - ANPED SUl, 2010, Londrina - Paraná. ANPED Sul. Londrina - PR: UEL, 2010. v. 1. p. 114.

NARCIZO, K. R.S. Uma análise sobre a importância de trabalhar educação ambiental nas escolas. Revista eletrônica Mestrado Educação Ambiental, v. 22, 2009.

PADUA, E. M. M. Metodologia da pesquisa: abordagem teórico prática. 13 ed. Campinas, SP. Papirus. 2007.

PEREIRA, L. F. Que infância estamos construindo? Folha de São Paulo, São Paulo, 12 out. 2007. Disponível em: <http://www.alana.org.br/CriancaConsumo/Biblioteca. aspx? $v=1 \&$ art=19>. Acesso em 28 de out. 2017.

REIGOTA, M. Desafios à educação ambiental escolar. In: CASCINO, F.; JACOBI, P.; OLIVEIRA, J. F. (orgs.) Educação, meio ambiente e cidadania: reflexões e experiências. São Paulo: SMA/CEAM, 1998.

RODRIGUEZ, J. M. M.; SILVA, E. V. da. Educação Ambiental e desenvolvimento sustentável: problemática, tendências e desafios. 2. ed. Fortaleza: Edições UFC, 2009.

SORRENTINO, M. Vinte anos de Tbilisi: cinco da Rio 92: a educação ambiental no Brasil. Debates Sócio ambientais, ano 2, n. 7, p. 3-5. 1997.

UNESCO, Organização das Nações Unidas para a Educação, a Ciência e a Cultura. Declaração da Conferência Intergovernamental sobre Educação Ambiental. 1977. Disponível em: http://www.mma.gov.br/port/sdi/ea/deds/pdfs/decltbilisi.pdf. Acesso em: 12 out. 2017. 